\title{
Designing for Culturally Contextualized Learning Activity Planning: Matching Learning Theories and Practice
}

\author{
Aparecido Fabiano Pinatti de Carvalho ${ }^{1,2}$, Junia Coutinho Anacleto ${ }^{1}$, \\ and Vania Paula de Almeida Neris ${ }^{1,3}$ \\ ${ }^{1}$ Advanced Interaction Lab, Computing Department, Federal University of São Carlos, \\ São Carlos, Brazil \\ ${ }^{2}$ Interaction Design Centre, Department of Computer Science and Information System, \\ University of Limerick, Limerick, Republic of Ireland \\ ${ }^{3}$ Computing Institute, State University of Campinas, Campinas, Brazil \\ fabiano.pinatti@ul.ie, junia@dc.ufscar.br, \\ neris@ic.unicamp.br
}

\begin{abstract}
Helping teachers in their activities has been an issue more and more explored in Computer Science. However, in order to support teachers effectively, it is necessary to understand their needs and to design tools that they can easily manage. One of those needs is undoubtedly to put in practice pedagogical principles. This paper presents the design of PACO-T, a tool for helping teachers in planning learning activities (LAs) supported by common sense knowledge, based on PACO, a seven-step textual framework for planning pedagogically suitable LAs. The design was based on the results of a case study carried out to investigate how teachers can plan LAs following PACO steps, using common sense knowledge from a common sense knowledge base collaboratively built through the web. Moreover, the interface design was ruled by a Web Design Pattern Language, attempting to improve the usability of the tool. PACO-T aims to help teachers to put in practice the recommendation for contextualizing LAs to the target group, found in several learning theories.
\end{abstract}

Keywords: e-learning, learning activity, contextualization, common sense knowledge, computer tool, design, Web Design Pattern, pedagogical issues.

\section{Introduction}

Technology can be an important support to education. Due to such support, e-learning practices are becoming more and more usual nowadays. Despite of the potential use of technology for education, understanding the needs of the actors involved in the process, i.e. teachers and students, is very important to allow the development of tools that can successfully support the educational process. For instance, in order to effectively support education, it is important to take into account pedagogical issues surrounding it in the development of learning technology, so that the developed solution can help teachers to put in practice such issues [1,2]. 
One of the main pedagogical issues discussed in relevant Learning Theories like those proposed by Freire [3], Freinet [4], Ausubel [5] and Gagné [6], is to contextualize the learning process to the target group's cultural background. A way of doing that, widely discussed by Freire [3], is to use common sense knowledge, i.e. the knowledge shared and accepted as true within a social community, spanning several knowledge categories such as temporal, spatial, social, cultural and so forth [7], for leveraging discussion and promoting effective learning.

Though a well-known pedagogical issue, until early 2006 it was not possible to find in the literature how teachers could easily access the common sense knowledge of their target group in computers, especially because the amount of information comprising common sense knowledge is huge - around 1,000,000,000 bits, according to Landauer [8]. However, since Lenat started working in Cyc, aiming to build a large scale common sense knowledge base [7], there have been advances in this area through the use of computational technology [9]. Making use of those advances, recent researches [10-13] have shown that common sense knowledge collected collaboratively through the web can be used to state the target group's previous knowledge and to identify its needs.

Therefore, this paper focus on the design of a computational tool that makes teachers able to access and to explore common sense knowledge, collected collaboratively through the web and stored in the knowledge base of the project OMCS-Br (Brazilian Open Mind Common Sense) [14], during the planning of learning activities (LAs). PACO-T is a common sense-aided Tool which guides teachers towards the planning of culturally contextualized LAs. It is based on PACO [15], a seven-step textual framework for planning pedagogically suitable LAs.

It is worth pointing out that the design of PACO-T was concerned about HCI (Human-Computer Interaction) issues, with the purpose of developing a tool under usability criteria, so that teachers can easily interact with it. For that, a case study was conducted to identify (1) how the process of teachers' planning LAs using PACO could be mapped into a computational tool; and (2) how common sense knowledge can help teachers answer questions brought up along the steps of PACO, so that they can contextualize their LAs to their target group, which can be either the students who are going to participate of a LA or the members of a social group with whom the students are going to interact after the LA in order to apply the knowledge acquired [10].

Still related to HCI issues, the design of the interfaces was ruled by a Pattern Language for designing web application proposed by Montero et al. [16], since the tool is a web application. Once Patterns are successful solutions for recurrent problems [17], the design of interface ruled by Patterns can lead to solutions already well disseminated among users that they will probably know and be able to deal with easily, which will consequently improve the system usability and accessibility.

The paper is organized as follows: section 2 discusses how common sense knowledge can be used for supporting teachers in planning LAs according to the proposal of the framework PACO, taking into account the results of the case study previously mentioned; section 3 presents the design of PACO-T, discusses some decisions for providing usability for the tool and goes over some details of its implementation; finally, section 4 presents some conclusion remarks and points to future works. 


\section{The Framework PACO and Common Sense Knowledge - A Case Study}

PACO is a textual framework designed to support teachers in Planning LAs supported by COmputers, which is composed by seven steps [15]:

1. To define the LA theme, target public and general goal;

2. To organize the LA topics;

3. To choose a pedagogical/methodological reference;

4. To plan the learning tasks;

5. To choose computer tools to support the activities execution;

6. To edit the learning objects which are going to be used in the LA ; and

7. To test pedagogical and technological issues.

The essence of PACO relies on the fact that the definition of the learning tasks and the selection of the computer tools to support their performance should be addressed by pedagogical issues and by characteristics of the target group. PACO has already been used by teachers from different areas such as computer science, nursing and occupational therapy, who have no previous knowledge about planning LAs supported by computers. The feedback received from these case studies showed that, even though someone does not have experience on planning LAs, s/he can do it by following the framework steps [15].

One of the LA planning made by nursing teachers was specially proposed to $(i)$ analyze the possibility of using common sense knowledge during the planning of LAs, in order to contextualize them to the target group's needs, and (ii) design a computational tool to support teachers with this task $[10,13,18]$. In the case study, two nursing teachers planned a LA to prepare their students on how to orient caregivers in the community from which the common sense knowledge was collected. Therefore, the educational context was composed by three actors [10]:

1. Nursing teachers, who had to plan a learning activity following PACO steps, taking into account the information stored in a common sense knowledge base;

2. Second year nursing students, who were going to be thought how to orient caregivers;

3. The population, whose members could become a caregiver, from which the common sense knowledge was collected.

The common sense knowledge was used to call the students' attention to the way which the population talked about requirements to be a caregiver or about procedures which might be taken while home caring a sick person. The students were presented points which they should emphasize during the orientation. Thus, the target group was members of the community where the common sense knowledge were collected from, who were going to take care of a sick person at home.

Through the case study, it was possible to identify how common sense knowledge could support teachers in answering questions brought up along the framework steps, as it is explained in the following. In that occasion, the common sense knowledge in the OMCS-Br knowledge base was semi-automatically organized in an on-line common sense matrix, taking into account specific parameters defined by the teachers involved in the LA planning - see [10] for more details. All the planning 
Table 1. Possible support offered by common sense knowledge in each step of PACO[10]

\begin{tabular}{c|l}
\hline Step & Support \\
\hline \multirow{4}{*}{1} & To define the LA theme. \\
\cline { 2 - 2 } & To compose the LA justification. \\
\cline { 2 - 2 } & To define the LA general goal. \\
\cline { 2 - 2 } 2 & $\begin{array}{l}\text { To define the LA specific goal. } \\
\text { students' needs. }\end{array}$ \\
\cline { 2 - 2 } & To decide the degree of detail with which each topic should be approached. \\
\hline 3 & $\begin{array}{l}\text { To reach pedagogical issues addressed in Freire's, Freinet's, Ausubel's and Gagné's } \\
\text { Learning Theories. }\end{array}$ \\
\hline 4 & To fit the LA tasks to the pedagogical/ methodological references adopted. \\
\cline { 2 - 2 } 5 & To know how the target group usually study. \\
\hline 6 & To know with which computer tools the target group is familiar. \\
\hline 7 & - \\
\hline
\end{tabular}

was followed and registered in field notes by a researcher who used to interact with the teachers in some moments in order to illuminate issues related to what he had observed. In those interactions the teachers explained their reasons for having done specific decisions for the planning, allowing the researcher to understand what they were thinking of. The teachers were also asked to think aloud, verbalizing their thinking during the planning. Everything was audio recorded and both the field notes and the audio were analyzed afterwards. Through the data analysis it was confirmed that common sense knowledge can support teachers during the planning of LAs using PACO in several different ways, as Table 1 summarizes.

Concerning the framework Step 1, it turned out that teachers could think of defining the LA theme taking into account the needs that they observed in the common sense knowledge available [18]. In the case study, although the LA theme had been previously well defined - how to orient people to home care a sick person -, teachers identified themes which could originate other LAs. One example is the theme "getting basic knowledge about nursing practices". By the analysis of the available OMCS-Br common sense knowledge, the teachers noticed that the population usually mentioned that, in order to home care a sick person, it is necessary to learn about basic nursing practices. From this evidence, the idea of planning a LA in the future about that theme came out.

Still related to the Step 1, it was also found out that common sense can help teachers to compose the LA justification, another task of PACO Step 1. For instance, in some situations teachers realized that some topics were not mentioned in the knowledge base, when they should be, or that the members of the target group misunderstood related topics, or even that the target group was very interested in the topic. Based on those evidences, teachers were able to compose the justification of promoting a LA on that theme.

In the same way, considering what was observed in the knowledge base, the teachers could define the general and the specific goals of their LA. For example, still considering the theme "getting basic knowledge about nursing practices", teachers told that they could propose as general goal of the new LA "to teach the population about 
basic nursing practices". The comment came out when the researcher who was observing the LA planning asked the teachers how they thought that the knowledge they were analyzing could help them define the LA goals. Moreover, according to the items they found in the knowledge base, they could propose specific goals such as "to teach the population about techniques to control a fever", or "to teach the population techniques to change the clothes of a sick person that cannot move", and so on.

Regarding the framework Step 2, where teachers have to define the topics they are going to approach in the LA, to organize these topics, and to define how specific they will be in each topic, the teachers could also collect evidences from the common sense knowledge base to help them with these tasks. In the case study, based on what they verified in the common sense knowledge from the OMCS-Br knowledge base, they selected topics such as "the importance of caregivers' having leisure" and "the diet of sick people" to be approached in the LA.

The first topic was proposed because the teachers realized that people failed to mention that a caregiver needs help to take care of a sick person at home when they were exploring the statements available in the common sense knowledge base. According to them, the common sense knowledge showed that people from the target group considered that, in order to home care a sick person, it is necessary to dedicate all their time to the task, forgetting to mention their own leisure, resting and comfort. This fact should be considered, according to the teachers, because the caregiver needs to rest in order not to become sick. Hence, this topic was emphasized during the LA, so that the nursing students remind the caregiver about the need of having someone else to share the responsibilities of home caring the sick person so that s/he can rest and can be well to perform the home care.

The second topic was chosen because people from the target group always mentioned that sick people like or need to eat soup. According to the teachers, this is not always true. Depending on the illness or its seriousness, the sick person can eat and sometimes has to eat other things besides soup. Thus they decided to add a topic in order to teach their students about which kind of diet is suitable for which situation and to make their students aware about the need for giving this orientation to the caregiver, since the caregiver possibly share the opinion that a sick person should eat only soup, once this is the common sense from her/his community.

About evidences that can help teachers to decide the degree of detail which they should give to specific topics during the LA planning, the teachers tended to propose several tasks to work on subjects that the target group failed to mention or misunderstood, such as the ones previously addressed, while they tended just to mention, in abstract terms, the subjects which they considered that the target group already knew. For example, the teachers found out in the knowledge base that the target group knew very well the main requirements that one should have in order to be a caregiver. In this case, they propose a simple activity to remind the students that they should check whether the person who is going to home care a sick person fits to the requirements for being a caregiver. They decided to keep this topic in the LA because they were concerned that, although the target group's members knew about the main requirements for being a caregiver, sometimes a person who does not fit to the requirements may have to home care a sick person.

In relation to Step 3, the case study showed that common sense knowledge can support teachers to plan LAs according to four Learning Theories [18]: Freire's [3], 
Freinet's [4], Ausubel [5], and Gagné [6]. As in the Step 3 teachers have to choose pedagogical/methodological references to plan the LA tasks, teachers are advised to select one of those Learning Theories, so that they can use common sense to plan the tasks that the students will perform to reach the LA goals.

Depending on the pedagogical/methodological references chosen for the task in Step 3, the planning of the tasks in Step 4 can also be supported by common sense knowledge. For example, Freire's Learning Theory suggests that teachers should make students build the new knowledge on their common sense. According to this theory, teachers should discuss with the students the reasons why they believe that some pieces of common sense knowledge are correct and then introduce the new knowledge correcting or complementing the previous knowledge [3]. Thus, adopting this pedagogical/ methodological reference, teachers can search on the common sense knowledge the pieces of knowledge they can use in the learning tasks. Ausubel's Theory defends a similar approach. According to Ausubel, in order to promote meaningful learning, teachers should make the students attach the new piece of knowledge to the knowledge which is already in their cognitive structure. Considering that common sense knowledge is part of the cognitive structure of all students, the planning of the learning tasks can be directed so that meaningful learning can take place. More details of how common sense can support these two Learning Theories and the others previously mentioned can be found in [2].

Besides the support to fit the LA tasks to the chosen pedagogical/methodological references, teachers can also search in the common sense knowledge base for information on how people from their target group usually study. For example, if teachers find out, in the knowledge base, statements such as "in order to get informed, one has to read" and "in order to learn, one has to study several books", they can interpret that people from that target group are used to reading and, therefore, propose some readings to discuss the topic. On the contrary, if teachers find out statements such as "to get informed, one has to watch television" and "one can learn a lot watching a movie", they can try to find some movies related to the LA and propose other kind of activities.

In the same way, teachers can search the common sense knowledge base for information about computer tools and try to figure out which tools are frequently used by people from their target group. In this manner, they can try to choose computer tools which the target group members are familiar with, avoiding that students have to spend lots of time to learn how to interact with a tool before starting to perform a task. This is the way that common sense can support teachers in PACO Step 5.

Finally, regarding the support that common sense can give in Step 6, a recent research has shown how common sense knowledge can be used for helping teachers to edit learning objects and fulfill their metadata in order to facilitate their discovery and reuse. See [19] for details.

\section{Designing PACO-T}

The case study previously presented allowed a requirements elicitation on issues that a computational tool should address for supporting teachers in planning contextualized LA in the same way that the teachers of the case study were able to do. From the 
elicitation, it was possible the computational design of PACO-T, which is presented along this section.

The requirements elicitation showed that a solution to effectively support teachers in planning common sense contextualized LAs according to the proposal of PACO, would be develop a question-based system to guide teachers in providing the necessary information for the LA planning. Therefore, it was decided to organize the questions that the tool would present to teachers in seven steps, as in the original proposal of the framework, since previous studies showed that this organization makes easier the teachers' task of planning LAs [15]. During these steps, teachers should be offered access to the common sense knowledge, so that they can use it in the same way that the nursing teachers could use during the case study LA planning.

In so doing, it was decided to use the resources of the OMCS-Br project, since it provides a framework for collecting and using common sense knowledge in computer applications [2, 14]. It was also decided to develop the tool for the Web platform, considering the facilities that the Web provides for accessing computer systems all over the world and the wide spread dissemination of Web technology. Nowadays more and more people get used to web technology in their work and personal life, using e-mails, electronic agendas, on-line shopping system and so forth, since they offer flexibility and fast solutions in a society where time is very restricted.

The tool was designed using the paper prototyping technique, since it is considered a low cost and suitable technique for eliciting and refining computer system requirements [20]. Thinking of achieving usability criteria in the tool, its interfaces were sketched following the Patterns of the Web Design Pattern Language proposed by Montero et al. [16], since that Pattern Language was proposed envisioning to improve usability in sites designed trough it [16] and PACO-T would basically be a web site where teachers would be able to plan LAs. The set of usability guidelines proposed by Nielsen for designing web systems [21] were also considered.

Figure 1 shows the prototype of the tool home page. Specifically for this paper, the paper prototype was freely translated into English, because the system is only available in Portuguese. The application of ten Patterns from the considered Pattern Language can be observed in that interface as it is explained in the following. To begin with the Patterns related to the whole interface, labeled with number 1 . This interface implements the Patterns Welcome and Homepage. According to [16], every single web system must provide a place that allows users to identify where they are. Providing a reception place where use and access conditions can be evaluated is the proposal of the Pattern Welcome. The other referred Pattern, Homepage, goes towards the need of providing a point of reference, which allows users to answer what they can get from that web site, how and when. The authors of the Pattern Language mention that usually the implementation of the Patterns Welcome and Homepage is the same many times. This is what happens in PACO-T.

Therefore, the interface in Figure 1 is proposed to allow teachers to identify where they are and what they can do in that place. The implementation of other Patterns of the Pattern Language gives support for these goals. For instance, the area in Figure 1 labeled with number 2 corresponds to the solution used in the system for the Pattern Tagline, which suggests the presentation of a statement summarizing the site purpose [16]. The text in area 7 also informs the user about the purpose of the site. That text was composed having in mind the suggestions of the Patterns Polyglot and Polite. 


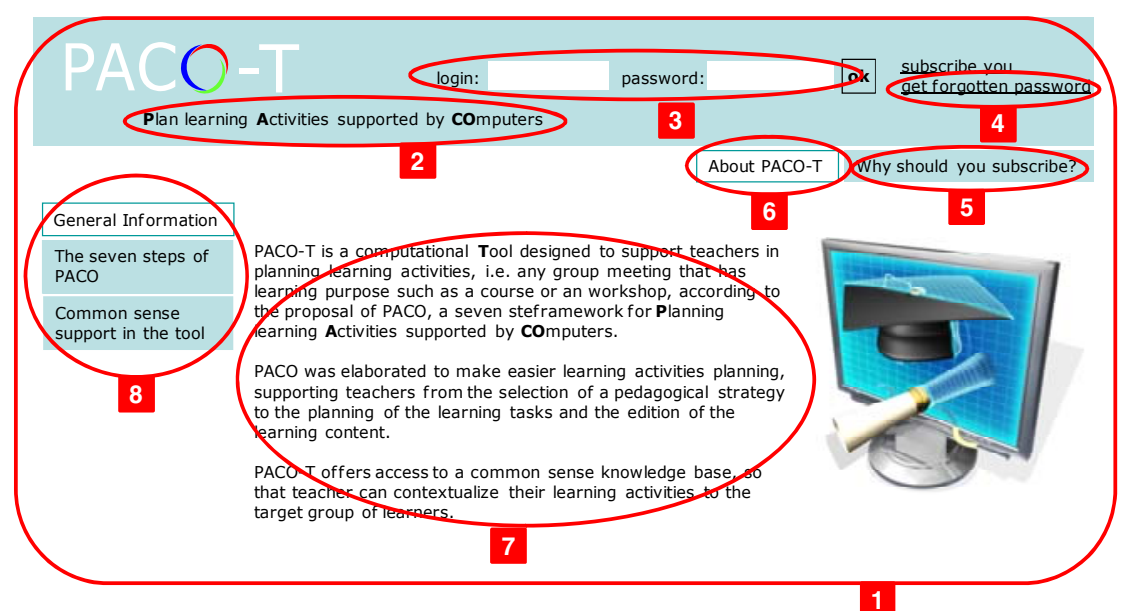

Fig. 1. PACO-T Home page

The first one suggests the use of a language that can be understood for the largest variety of people who can access the site. The second one advises to care about the visitors. Thinking about those suggestions, a short text was composed, explaining the purpose of the tool, using a simple vocabulary and suggestive examples to illustrate terms that could not be understood by ordinary people who visited the site, such as the concept of LA. The Polite can also be noticed in area 2, since the system cares about explaining to the users why they should register themselves on the site.

Other Patterns present in the interface showed in Figure 1 are: Form (area 3), Second Chance (area 4), About us (area 6), Indication (areas 4, 5, 6 and all other links available in the interface) and Location (in general, the whole interface that allows teachers to recognize that they are in the site/tool PACO-T and, specifically, the areas 6 and 8 that allows teachers to know that they are in the page "General information" of the section "About PACO-T"). The tool also applies the Pattern Danger, which says that a site should be designed to need as few plug-ins as possible for working [16]. PACO-T does not require any specific plug-in to work.

Regarding the use of usability guidelines in the design, the anchors of the links in the pages were designed to be as meaningful as possible, i.e. the text of the links should allow teachers to know what information or functionality they are going to get if they click on it. Another guideline followed was to use the imperative form of the verbs in links that corresponds to functionalities of the system. For example, the verbs of the links "subscribe you" and "get forgotten password" are in imperative form.

Thinking of usability issues, each step was split in several sub-steps in order to reduce the amount of information with which teachers should deal in each interface. The left navigation tree presented in Figure 2 allows seeing such organization in substeps. As Figure 2 shows, there are five sub-steps in PACO-T Step 1: (i) Define the LA title; (ii) Define the target group's profile; (iii) Define the theme, (iv) Define the objectives and $(v)$ Add complementary information.

Note that the interface was designed for guiding teachers along the interaction. So, it is worth calling the attention for the usability guidelines applied in the interface at 


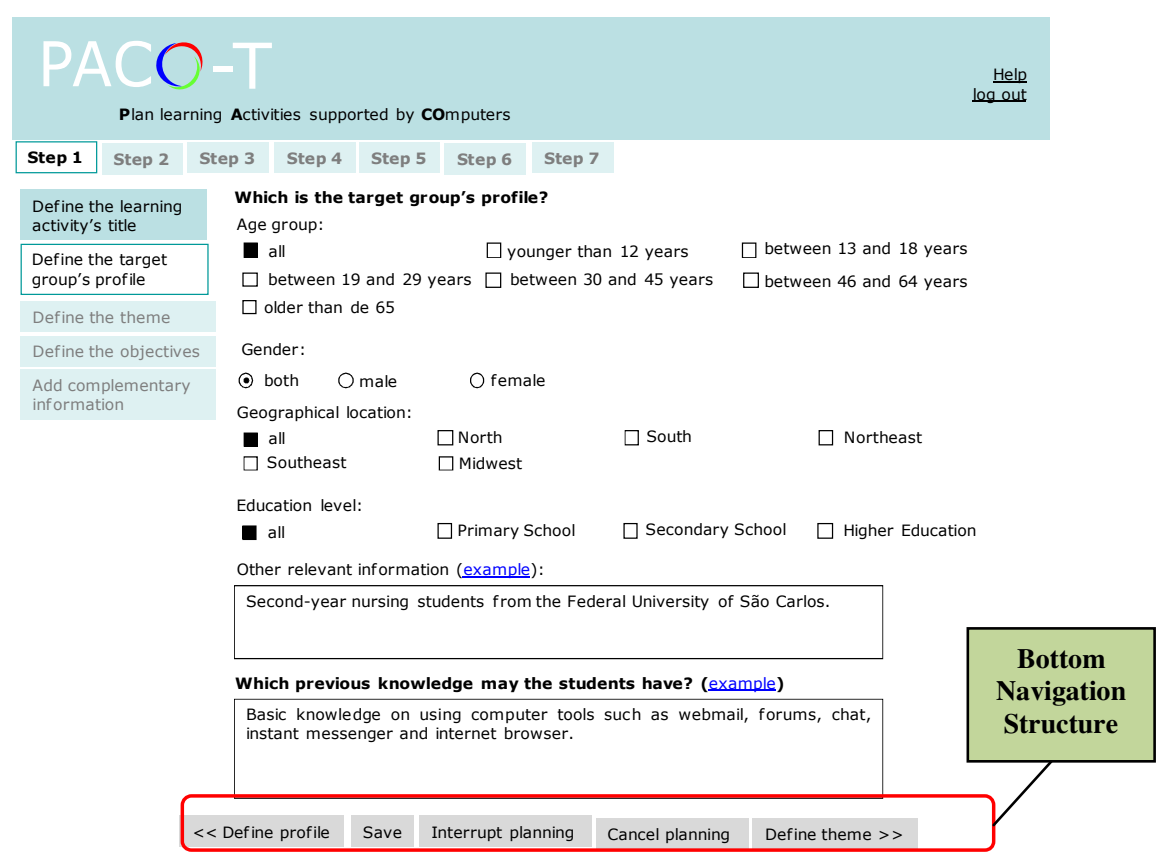

Fig. 2. PACO-T Step 1 - Define the target group's profile

Figure 2. The interface tells exactly where the teacher is (Step1/Sub-step 2 - Define the target group's profile). Moreover, it tells which Step/sub-steps have been already concluded. In this example, no step has been concluded yet, as it can be noticed by the weaker color of the tabs correspondent to Steps 2 to 7 . Nonetheless, regarding the Step 1, it can be noticed that sub-step 1, "Define the learning activity title" has been already done. The other sub-steps have not been done yet, as the weaker colors indicate. This is a usability guideline for designing web systems proposed by Nielsen [21] and also a solution for the Patterns Location and Indication [16].

In addition to that, the interfaces were designed to prevent user errors. For example, links and tabs that cannot be clicked yet (the ones in weaker colors) are deactivated. They are kept in the interface so that the user can have an idea in which point of the planning they are, according to the solution proposed by the Pattern Indication[16]. However, as PACO defines that the planning should happen sequentially, since a step depends on information given in previous steps, teachers can only proceed when they finished filling the form in and clicking on the button to go to the next step, available in the bottom navigation structure. These buttons always have the symbol " $>>$ " indicating the action of going forth to the next step.

Teachers also have total control of the system, one of the main usability issues. They can go back to a previous step they have already concluded and modifies what they want; they can interrupt the planning and continue later; they can cancel the planning and so forth. Furthermore, teachers can ask for information about the step where they are by clicking on the link "Help" or get sample information about how they should answer each question on the interface by clicking on the link "example" 
available after the question. All of those design concerns were explored in the interface taking into account the orientation of the Pattern Language used to guide the design and the usability guidelines presented in [21].

Along the system, teachers face with questions such as the ones shown in Figure 2. These questions support them in planning the desired LA and the questions were defined taking into account the information required by PACO.

The interface in Figure 2 precedes the first sub-step in PACO-T where teachers can use the support offered by common sense knowledge. It is an important interface, because it is where teachers define the LA target group's profile and, consequently, allows the system to filter the common sense knowledge base that will be used so that the tool presents to teachers only common sense knowledge collected from people with the same profile of their target group. Regarding implementation issues, that interface allows the system to connect to a specific semantic network of the OMCS$\mathrm{Br}$ project. Semantic networks are the knowledge representation adopted in OMCS-Br (for details about the decision of representing the knowledge as a semantic network, see $[2,14,22])$. In OMCS-Br, there are several semantics networks representing the knowledge collected in the project, which are called ConceptNets. This is because OMCS-Br offers the possibility of generating a ConceptNet to each combination of the profile parameters established for the project (age group, gender or geographical location and education level). Figure 3 presents an interface where common sense knowledge can be helpful for teachers.

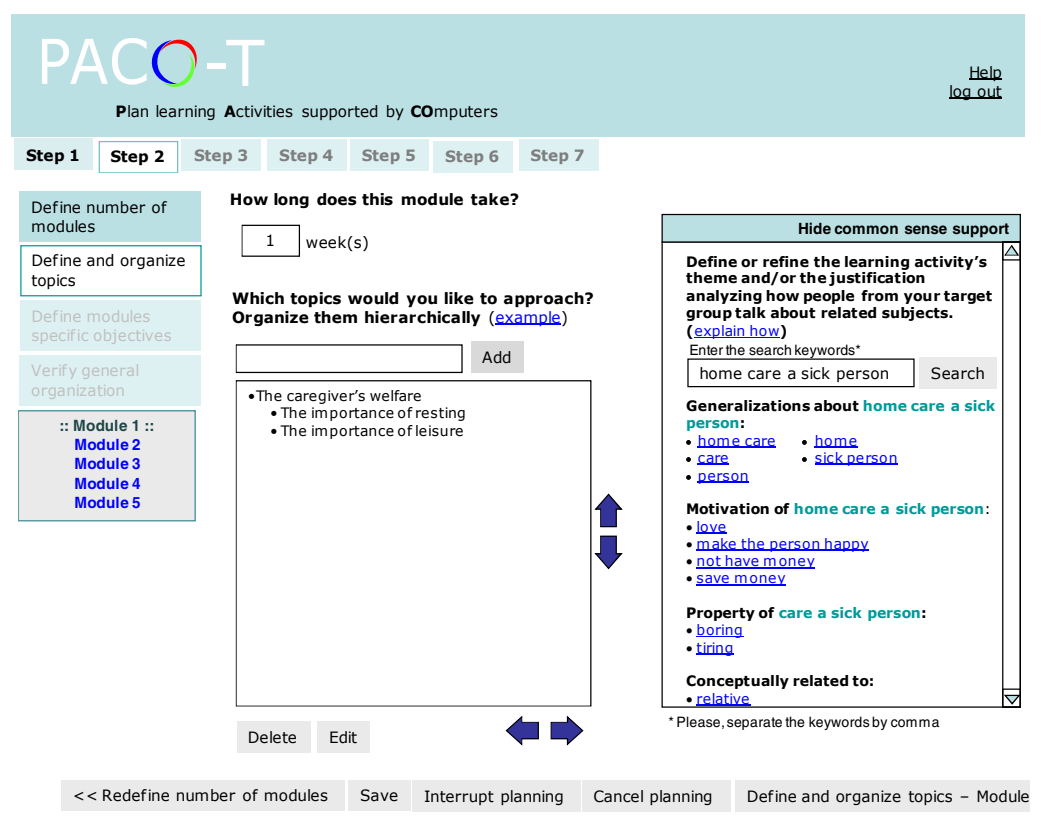

Fig. 3. Computational Representation of PACO - Step 2 - Define and Organize Topics 
In this interface, teachers should define the topics that they want to approach in the LA. In order to analyze how people talk about subjects of interest and decide for the topics of the LA, teachers have to provide some keywords in the search text field and click on the button "Search" or to add a new topic in the list of topics. In doing so, the system sends the keywords to a function in the API called GetContext(). The GetContext() retrieves the context related to the provided keywords. It tries to find nodes in the ConceptNet equals to the keywords and then performs spreading activation radiating outward from the nodes found [22], i.e. it performs a semantic expansion on the keywords provided. After finding words related to the context, the system sends the words which relevance to the context is greater than $30 \%$ to the DisplayNode() function. This function receives a word or a phrase and returns the relations in the ConceptNet which have a node equal to the provided entry. In this way, the words returned by the GetContext() function are sent one by one to the DisplayNode() and five relation at most of each relation type returned are considered.

For instance, consider the example in Figure 3. The teacher provided the keyword "home care a sick person". The system sends to the GetContext() the following keywords: "home care a sick person", "home", "care", "sick", "person". As a rule, composed keywords are split before being sent to GetContext() in order to increase the possibility of return. It is possible to do this without impacting in the desired context, because GetContext() retrieves the contextual intersection of multiple concepts [22]. In the example previously described, some words and expressions in the context returned by GetContext() that have relevance greater than $30 \%$ were: "home care a sick person", "home care", "care a sick person", "love", "save money", "relatives", "have time" and "be prepared". Each word was sent to the DisplayNode() function. For example, to the expression "home care a sick person" some relations returned by DisplayNode() were:

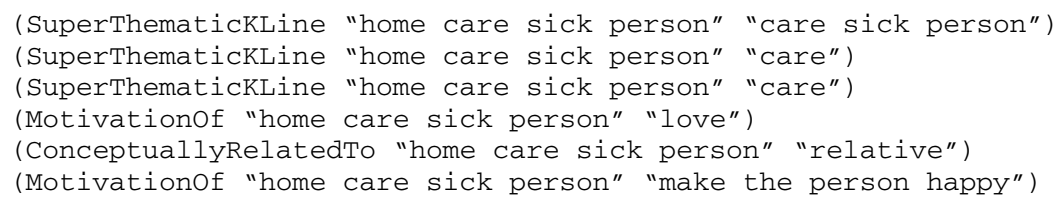

SuperThematicKLine, ConceptuallyRelatedTo and MotivationOf are some of the relation types in ConceptNet. All those relation types are based on Minsky's Theory about the mind [23].

After retrieving the relations from ConceptNet, PACO-T maps them to natural language and, then, presents it to teachers. Figure 4 exemplifies the mapping performed by PACO-T before showing the common sense relations to teachers.

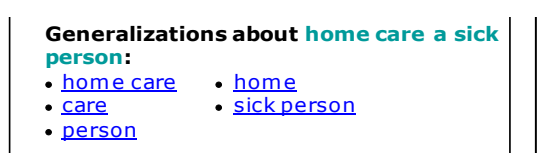

Fig. 4. SuperThematicKLine mapped to Natural Language 
The relation type mapped in Figure 4 is the SuperThematicKLine. That relation type refers to the generalization/specialization principle and, therefore, the more abstract concepts are presented as generalizations for the more specific concept. In the example, the concepts "home care", "care", "person", "home" and "sick person" can be considered in some way more abstract that the concept "home care a sick person".

Note that the items in Figure 4 are presented as links. Clicking on the link, the system performs a new search in the ConceptNet, using as keyword the text of the link and updates the information in the common sense support box. This allows teachers to navigate among the concepts previously presented and to analyze how people with the same profile of their target group talk about related subjects. After the analysis, they can use the information gotten in one of the ways discussed in section 2 . The common sense support box is always presented when teachers are asked to decide something based on this kind of knowledge.

By following the steps of the computational representation of $\mathrm{PACO}$, answering the questions presented in each step and exploring the available common sense knowledge, teachers can plan their LAs taking into account pedagogical issues and fit it to their target group needs. It is worth pointing out that teachers can hide the common sense support box in any moment. At the end of the planning, teachers can export the LA plan to text format so that they can print it.

Figure 5, though in Portuguese, presents the same interface showed in Figure 3 after implementation. It can be observed that the implementation is in conformance with the design of the interfaces previous discussed. The interfaces are currently in Portuguese but it is intended to make possible their internationalization. Having this in mind, Java, JSF, Spring, Ajax and Hibernate have been used for the implementation, since they offer resources for easily internationalize interfaces.

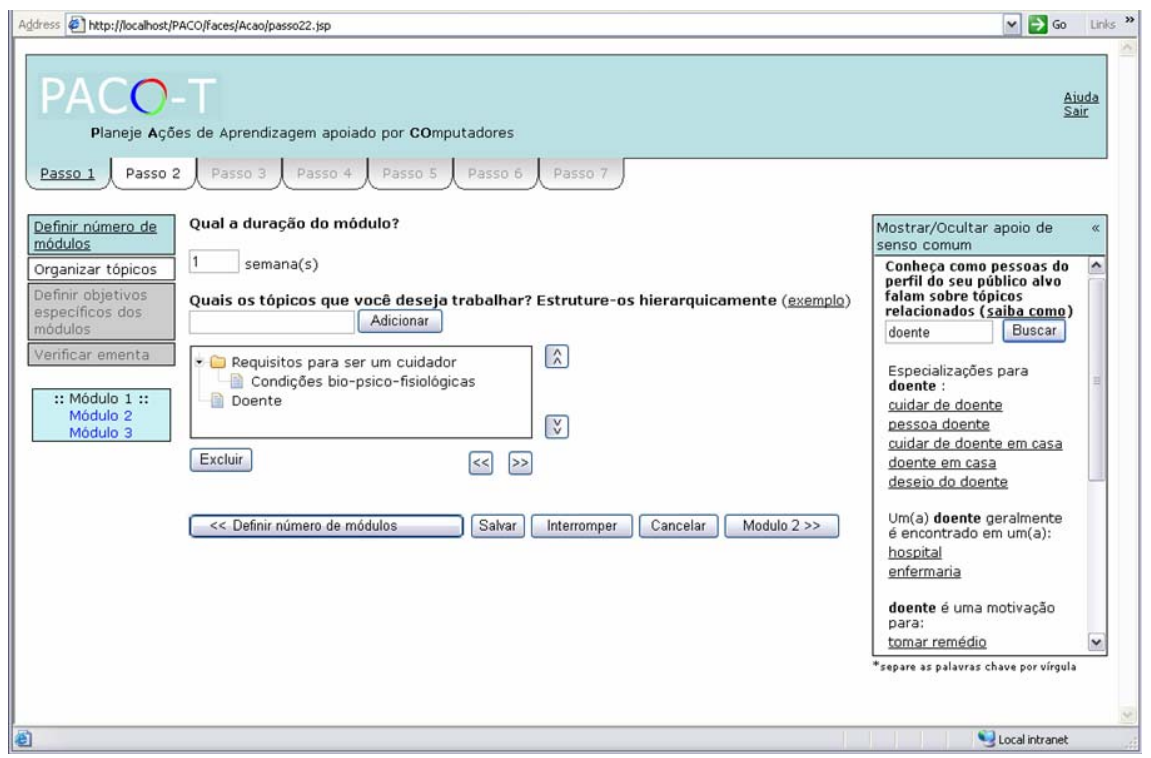

Fig. 5. PACO-T Functional Interface - Step 2 - Define and organize topics 


\section{Conclusions and Future Works}

Contextualizing learning is one of the main pedagogical issues found in the literature and common sense knowledge can be used for this purpose. This paper presented the design process of a tool to support teachers in addressing such issue during the planning of LAs. The design was made considering requirements elicited from teachers by the conduction of a case study.

In the case study, PACO framework was used as the theoretical reference for supporting LA planning and common sense knowledge from the OMCS-Br knowledge base was made available for teachers to help them answering questions brought during the steps of PACO, so that the final LA was culturally contextualized to its target group.

The tool can make the task of planning LAs easier to teachers and to give them conditions to plan LAs that fit to their target group's needs and, therefore, to promote effective learning, putting in practice principle from renowned Learning Theories. In addition to that, the availability of common sense knowledge collected from people with the same profile of the teachers' target group is a useful tool for contextualization that still cannot be found in any other tools for planning LAs. Furthermore, interfaces designed were performed following the Web Design Pattern Language of Montero et al. [16], aiming to address usability. Making the tool available on the web, implementing it using technologies such JSF and keeping a simple language were an attempt of addressing accessibility issues.

As future work, it is proposed usability and accessibility tests using the tool in order to improve it, refining its interfaces to make it even more simple and intuitive to use. Still, it is proposed to implement accessibility issues to make the site the most compatible with assistive technology as possible.

Acknowledgements. We thank FAPESP and CAPES for partially support this project, Prof. Silvia Zem-Mascarenhas, Prof. Rosely M. de Figueiredo and all students from DEnf/UFSCar, who have participated on the learning activity planning and execution, the undergraduates Raphael da Silva Santos and Paulo Papotti, who has worked hard on the implementation of PACO-T, and Henry Lieberman from MIT MediaLab for the initial collaboration with the OMCS-Br project.

\section{References}

1. Conole, G., Fill, K.: A Learning Design Toolkit to Create Pedagogically Effective Learning Activities. Journal of Interactive Media in Education. Special Issue on Portable Learning, 1-16 (2005)

2. Anacleto, J.C., de Carvalho, A.F.P., Ferreira, A.M., Pereira, E.N., Carlos, A.J.F.: Common Sense-based Applications to Advance Personalized Learning. In: The 2008 International Conference on System, Man and Cybernetics (IEEE SMC 2008), pp. 1-10. IEEE Computer Society, Los Alamitos (2008)

3. Freire, P.: Pedagogia da Autonomia: Saberes Necessários à Prática Educativa, 31th edn. Paz e Terra, São Paulo (1996) (in Portuguese)

4. Freinet, C.: Education Through Work: A Model for Child Centered Learning. Edwin Mellen Press, New York (1993)

5. Ausubel, D.P.: Educational Psychology: A Cognitive View. Holt, Rinehart and Winston, New York (1968) 
6. Gagné, R.M.: The Conditions of Learning, 3rd edn. Holt, Rinehart and Winston, New York (1974)

7. Lenat, D.B., Guha, R.V., Pittman, K., Pratt, D., Shepherd, M.: Cyc: Toward Programs with Common Sense. Communications of the ACM 33(8), 30-49 (1990)

8. Landauer, T.K.: How much do people remember? Some estimates of the quantity of learned information in long-term memory. Cognitive Science 10, 477-493 (1986)

9. Panton, K., Matuszek, C., Lenat, D., Schneider, D., Witbrock, M., Siegel, N., Shepard, B.: Common Sense Reasoning - From Cyc to Intelligent Assistant. In: Cai, Y., Abascal, J. (eds.) Ambient Intelligence in Everyday Life. LNCS, vol. 3864, pp. 1-31. Springer, Heidelberg (2006)

10. de Carvalho, A.F.P., Anacleto, J.C., Zem-Mascarenhas, S.H.: Learning Activities on Health Care Supported by Common Sense Knowledge. In: The 23rd Annual ACM Symposium on Applied Computing (SAC 2008), pp. 1385-1389. ACM Press, New York (2008)

11. de Carvalho, A.F.P., Anacleto, J.C., Neris, V.P.A.: Supporting Teachers to Plan Culturally Contextualized Learning Activities. In: Kendall, M., Samways, B. (eds.) Learning to Live in the Knowledge Society, IFIP International Federation for Information Processing, vol. 281, pp. 171-174. Springer, Boston (2008)

12. Anacleto, J.C., Godoi, M.S., de Carvalho, A.F.P., Lieberman, H.: A Common Sense-Based OnLine Assistant for Training Employees. In: Baranauskas, C., Palanque, P., Abascal, J., Barbosa, S.D.J. (eds.) INTERACT 2007. LNCS, vol. 4662, pp. 243-254. Springer, Heidelberg (2007)

13. Anacleto, J.C., de Carvalho, A.F.P., Neris, V.P.A., Godoi, M.S., Talarico Neto, A.: How Can Common Sense Support Instructors with Distance Educations? In: The 2006 Brazilian Symposium on Informatics and Education (SBIE 2006), pp. 217-226. Brazilian Computing Society, Porto Alegre (2006)

14. Anacleto, J.C., de Carvalho, A.F.P., Pereira, E.N., Ferreira, A.M., Carlos, A.J.F.: Machines with Good Sense: How Can Computers Become Capable of Sensible Reasoning? In: Bramer, M. (ed.) Artificial Intelligence in Theory and Practice II, IFIP International Federation for Information Processing, vol. 276, pp. 195-204. Springer, Boston (2008)

15. Neris, V.P.A., Anacleto, J.C., Zem-Mascarenhas, S.H., De Carvalho, A.F.P.: PACO - A Framework for Planning Learning Activities Supported by Computers. In: The 18th Brazilian Symposium on Informatics in Education (SBIE 2007), pp. 597-606. Brazilian Computing Society, Porto Alegre (2007)

16. Montero, F., Lozano, M., González, P., Ramos, I.: A First Approach to Design Web Sites by Using Patterns. In: The 2002 VikingPLoP Conference (2002)

17. Alexander, C., Ishikawa, S., Silverstein, M., Jacobson, M., Fiksdahl-King, I., Angel, S.A.: A Pattern Language: Towns, Buildings, Construction. Oxford University Press, New York (1978)

18. de Carvalho, A.F.P., Anacleto, J.C., Zem-Mascarenhas, S.H.: Planning Learning Activities Pedagogically Suitable by Using Common Sense Knowledge. In: The 16th International Conference on Computing (CIC 2007), April 11, 2009. IEEE CS Press, New York (2009), http://magno-congreso.cic.ipn.mx/CD-2007/IEEE/index.htm

19. Anacleto, J.C., Carlos, A.J.F., de Carvalho, A.F.P., Godoi, M.S.: Using Common Sense Knowledge to Support Learning Objects Edition and Discovery for Reuse. In: The 13th Brazilian Symposium on Multimedia and the Web (WebMedia 2007), pp. 290-297. Brazilian Computing Society, Porto Alegre (2007)

20. Snyder, C.: Paper Prototyping: The Fast and Easy Way to Design and Refine User Interfaces. Morgan Kaufmann, San Francisco (2003)

21. Nielsen, J.: Designing Web Usability. Peachpit Press (1999)

22. Liu, H., Singh, P.: ConceptNet: a Practical Commonsense Reasoning Toolkit. BT Technology Journal 22(4), 221-226 (2004)

23. Minsky, M.: The Society of Mind. Simon and Schuster, New York (1988) 